\title{
The Regularities of Change of Organic Compounds Oxidation Activation Energy in Aqueous Medium Under Supercritical Fluid Conditions
}

\author{
Zufar Ibragimovich Zaripov, Almaz Uralovich Aetov, Farid Muhamedovich Gumerov, Valery \\ Grigorievich Nikitin, Sergey Valerevich Mazanov, Asia Radifovna Gabitova, Alexander Ivanovich \\ Kurdyukov \\ ${ }^{1}$ Kazan National Research Technological University, Kazan, Russia
}

\begin{abstract}
The regularities of changes in the activation energy as a function of reduced state parameters, characteristics of the molecular field (dielectric constant, polarity) of the oxidized reactant and the oxidation reaction medium of saturated monohydric alcohols and acids in an aqueous medium under supercritical fluid conditions are revealed. A generalized dependence is obtained for the activation energy as a function of the difference between the polarities of the oxidizable reagent and the reaction medium, which describes the literature data with an acceptable error of $\pm 25 \%$. The capabilities of the method are confirmed by studies of the kinetics of the oleic acid oxidation by hydrogen peroxide in an aqueous medium under supercritical fluid conditions in the temperature range $673-723 \mathrm{~K}$ and a pressure of $29.4 \mathrm{MPa}$. The reaction rate constant and activation energy are determined. The activation energy of the oleic acid oxidation reaction by hydrogen peroxide in an aqueous medium under supercritical fluid conditions $\mathrm{Ea}=-104.8 \mathrm{~kJ} * \mathrm{~mol}-1$ differs by no more than $11 \%$.
\end{abstract}

Key words: water, oleic acid, hydrogen peroxide, emulsion, double and triple mixtures, SCWO, rate constant, activation energy, dielectric constant.

\section{INTRODUCTION}

The oxidation technology, implemented in a supercritical aqueous environment (SCWO), is one of the environmentally friendly ways of processing industrial and household waste [1-6]. Under supercritical fluid conditions, water [7-9] is an excellent solvent that can increase the intensity of heat and mass transfer processes and accelerate chemical reactions. The processes of organic compounds oxidation in a supercritical aqueous medium occur with the formation of carbon dioxide and water, and nitrogen-containing with the formation of nitrogen and nitrogen peroxide. The study of chemical reactions carried out in SCF-medium is given considerable attention [5, 10-14]. At the same time, despite the large amount of research conducted in this area, it can be stated that not all aspects of this issue are equally studied. The problem of information lack often concerns such sections as the thermodynamic behavior of the reaction mixture, reaction kinetics and thermal effects, which are key in developing mathematical models, designing and optimizing processes implemented in supercritical water conditions.

Most of the chemical production wastes are aqueous solutions of organic and inorganic compounds containing valuable components that undergo various transformations as a result of processing, purification and utilization. To establish the interdependence of the reaction rate, thermodynamic conditions and physicochemical properties of the reagents, theoretical and experimental studies of these characteristics as applied to the "water-acid" system were carried out.

For the studies, the reaction of oleic acid oxidation (one of the components of rapeseed runoff [13]) with hydrogen peroxide in a supercritical aqueous medium was selected. The choice of this model system is due to the presence of some data on the kinetic characteristics of this reaction, carried out at various parameters of the state with various oxidizing agents [15-18]. At the same time, there is no information on thermodynamic properties, especially in the near-critical (subcritical) state region. As for the thermophysical properties of the individual components of this mixture, they are studied in detail and are well known [19-22]. The oxidation of the components of aqueous solutions with hydrogen peroxide is well known [23]. A detailed consideration of the chemical specificity of oxidation with hydrogen peroxide in aqueous solutions is given in [24]. The authors of this work note that there is no fundamental difference in the elementary acts of the corresponding reactions that take place under normal and supercritical fluid conditions. In this sense, everything is determined by the energetics of the processes and their thermodynamic equilibrium. However, under SCF-conditions, alcohols, water, carboxylic acids exist and react mainly in the form of various dimer associates, the nature of which is due to hydrogen bonds, and the more complex solvate-associative specificity is characteristic for normal conditions and close to them. For supercritical fluids, elementary acts of simple associates become real, which under normal conditions have vanishingly small values of the constants of the forward reaction directions and which in the latter case are often possible only under the influence of catalysts of a different nature. It is known from the literature that the reaction of hydrogen peroxide decomposition often 
proceeds via a radical-chain mechanism [19, 24], while it is generally accepted that impurity amounts of catalytic agents are responsible for initiating free radicals. So, under the influence of ions, the formation of a very unstable radical anion $\left[\mathrm{H}_{2} \mathrm{O}_{2}\right]^{-}$, which immediately decomposes into the $\mathrm{OH}^{-}$ anion and the free and very active hydroxyl radical $\mathrm{OH}^{*}$, which can react with organic compounds as well as with the peroxide itself, and generate a less active hydroperoxyl radical $\mathrm{HO}_{2}$ and molecular oxygen. The hydrocarbons oxidation process proceeds by a free-radical mechanism.

The primary oxidation reaction products are hydroperoxides:

$$
\mathrm{R}-\mathrm{H} \underset{-\mathrm{HX}}{\stackrel{\mathrm{X}}{\longrightarrow}} \mathrm{R} \cdot \stackrel{\mathrm{O}_{2}}{\longrightarrow} \mathrm{R}-\mathrm{O}-\mathrm{O} \cdot \stackrel{\mathrm{RH}}{-\mathrm{R}} \cdot \mathrm{R}-\mathrm{O}-\mathrm{OH}
$$

where $\mathrm{R}$ - hydrocarbon radical of the lipid.

Reactive oxygen species $\left(\mathrm{HO}^{*}, \mathrm{H}_{2} \mathrm{O}_{2}, \mathrm{O}_{2}{ }^{*}\right.$ ) initiate free radical chain reactions. Fatty acids containing double bonds separated by a $\mathrm{CH}_{2}$-group are most affected by free radicals. Hydroxyl radicals attack an unsaturated acid molecule via a methylene group adjacent to a double bond. In this case, a radical is formed, stabilized by the participation of the unpaired electron in conjugation with the $\pi$-bonds electrons. Further, the organic radical interacts with the biradical oxygen molecule to form unstable hydroperoxides. Further decomposition of hydroperoxides, which are highly unstable compounds, is accompanied by the formation of aldehydes, which are oxidized to shortened chain carboxylic acids - the final reaction products. As for the other reaction directions of the oleic acid decomposition with hydrogen peroxide under different conditions, they are considered in detail in $[17,18]$.

\section{EXPERIMENTAL}

A study of the kinetics of the oleic acid with hydrogen peroxide aqueous emulsion oxidation under SCF conditions was carried out on a batch type experimental setup with molar ratios of water - oleic acid - hydrogen peroxide 0.96:0.008:0.032 in the temperature range $673-723 \mathrm{~K}$ and pressure $29.4 \mathrm{MPa}$. Features of the experimental setup and measurement methods are given in [13].

The following reagents were used:

- oleic acid of the grade "KhCh" ( $=1.4602,=910.1 \mathrm{~kg} / \mathrm{m} 3)$;

- an aqueous solution of hydrogen peroxide according to GOST 177-88 (OKP 212352 0100) with a mass fraction of peroxide of $36.43 \%(=1.3563,=1136 \mathrm{~kg} / \mathrm{m})$;

- water (bidistillate: $=1.3329,=997.1 \mathrm{~kg} / \mathrm{m}$ );

- magnesium sulfate " KhCh " GOST 4523-77 ( = 2660 кг/м3);
- diethyl ether "KhCh " GOST 22300-76 ( =1,3526, = 713 $\mathrm{kg} / \mathrm{m} 3$ ).

Oleic acid at room temperature does not mix and does not dissolve in water. In order to create a homogeneous mixture (emulsion), ultrasonic treatment of the two-phase mixture was performed. As a result of joint ultrasonic treatment of water and oleic acid, carried out under room (standart) conditions, a stable emulsion is obtained and the contact area of the phases increases significantly. Even more, the contact area of the phases increases with the transition from room to supercritical fluid conditions. The latter is due to the increase in the dissolving capacity of the aqueous medium, the dissolution of a part of the dispersed phase (oleic acid) and, as a result, a decrease in the geometric dimensions of the dispersed particles.

For the preparation of the emulsion ultrasonic emulsifier brand "UIP1000HD" of the German company Hielscher are used. Emulsification of a two-phase mixture of initial reagents increases the contact area of the phases, and accordingly, the rate of chemical reaction [25].

The following method of emulsion preparation was used: distilled water and oleic acid in specified ratios are poured into the emulsifier cuvette and subjected to ultrasonic action at a frequency of $21,000 \mathrm{~Hz}$ for 10 minutes. Next, the obtained sample of the emulsion is removed from the cuvette and is used to determine the chemical oxygen demand (COD), refractive index and density, as well as to study the kinetics of the reaction in the corresponding range of state parameters. Acceptable quality of the emulsion, determined by the nature of the components of the emulsified mixture, the frequency of the ultrasonic wave and the duration of the treatment procedure [25], is characterized by the stability for a period of time ( 1 week) required for the above-mentioned measurements.

As an integral indicator of the efficiency of the organic waste decomposition, the method of COD analysis was chosen [26], since the COD indicator is one of the main qualitative indicators of the organic compounds content in drinking, natural and waste waters.

The determination of the COD of the samples under investigation in this work was carried out by the express method using the T70 automatic titrator manufactured by Mettler Toledo using the combined platinum DMi140-SC electrode with a porous ceramic diaphragm.

Chromatographic analysis of the reaction product samples for the presence of oleic acid was carried out on a DFS Thermo Electron Corporation instrument (Germany). An ID-BP5X capillary column (an analogue of DB-5MS) of the Australian company SGE (Scientific Glass Engineering) with a length of $50 \mathrm{~m}$ and a diameter of $0.32 \mathrm{~mm}$ was used. The chemical composition of the phase is represented by $5 \%$ diphenyl and 
95\% dimethylpolysiloxane with a phase layer thickness of $0.32 \mu \mathrm{m}$. The carrier gas is helium. Mass spectral data processing was performed using the Xcalibur program. A sample volume of $0.1 \mu \mathrm{l}$ was dissolved in ethanol in a 1:1 ratio. The heating of the column is carried out in the program mode by the sections:

- initial temperature - 393K (1 min);

- heating rate $20 \mathrm{~K} / \mathrm{min}$ to $553 \mathrm{~K}$;

- Exposure - 20 minutes.

The product of the reaction of oleic acid oxidation with hydrogen peroxide under supercritical water was extracted with diethyl ether and then dried over magnesium sulfate. Diethyl ether is removed on a rotary evaporator brand N-1200A (EYELA, Japan). Further, IR-Fourier spectra of the samples were obtained (light yellow oily solutions) and the refractive indices of all six samples were determined. We used a Nicolet iS10 FTIR spectrometer, a universal instrument for conducting analyzes in the middle and near IR spectral regions.

The prepared emulsion is poured into a $40 \mathrm{ml}$ reactor. Hydrogen peroxide ( $\mathrm{H} 2 \mathrm{O} 2$ ) is added in an appropriate proportion. After reaching the regime parameters of the reaction, its duration is counted from 10 to 30 minutes. Sampling is done. After cooling, the samples are determined by their density and viscosity, the analysis of COD.

The efficiency of the oxidation process is calculated by the following equation [27].

$$
X=1-\frac{C O D t}{C O D i n}
$$

where and - indicators of COD after and before the oxidation reaction in an aqueous medium under SCF conditions, $\mathrm{mgO} 2 / \mathrm{l}$. was determined at a temperature of $298 \mathrm{~K}$ and amounted to $44612 \mathrm{mgO} / \mathrm{l}$.

The excess oxygen used is calculated by the following equation [28]:

$$
O_{2}(\%)=\frac{\left[O_{2}\right]_{a}}{\left[O_{2}\right]_{z}} \times 100
$$

where [O2]a - the concentration of oxygen obtained in the event of complete destruction of the hydrogen peroxide supplied to the reactor, mmol*l-1; [O2]s - stoichiometric oxygen concentration, mmol*1-1. According to the calculation data, the excess of oxygen was $\sim 200 \%$.

With regard to the issue of mutual solubility of the oxidized reagent and the reaction medium, it seems logical to recall the rule of V.K. Semenchenko [29], according to which: "the solubility of a substance passes through a maximum among solvents arranged according to the increasing value of intermolecular interaction in them; the maximum corresponds to the solvent whose molecular field is close to the molecular field of the dissolved substance". The important characteristics of the electrical properties of a molecule or molecular field are polarizability, dipole moment, and dielectric constant. In [30], it is pointed out that it is preferable to use the dielectric constant in this case.

The literature data on the dielectric constant $\varepsilon$ of many substances are usually limited to atmospheric pressure and a small range of temperature variations [31, 32]. This is due to the difficulties of measuring the dielectric constant at high temperatures and pressures, and especially in the near-critical region of the state. In the temperature range of $298-800 \mathrm{~K}$, the dielectric constant of water varies from 78.0 to 3.0 [31], whereas the dielectric constant of oleic acid remains almost unchanged and takes a value close to $\varepsilon=1.5$ [33].

The dielectric constant $\varepsilon$ of the main components is calculated based on the values of molecular polarizability $\mathrm{p}$ using the following equation [34]

$$
p=\frac{(\varepsilon-1) \cdot(2 \varepsilon+1)}{9 \varepsilon}
$$

The molecular polarizability $\mathrm{p}$ of hydrogen peroxide and oleic acid is known only at atmospheric pressure [32,33]. To calculate the molecular polarizability $\mathrm{p}$ of hydrogen peroxide in a wide range of state parameters used the relation [34]:

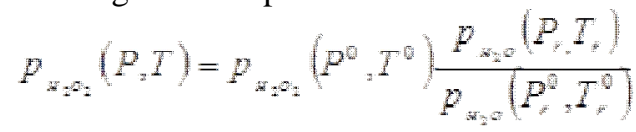

where $\quad P_{r}=\frac{P}{P_{c_{\mathrm{H}_{2} \mathrm{O}_{2}}} / P_{c_{\mathrm{H}_{2} \mathrm{O}}}} ; \quad P_{r}^{0}=\frac{P^{0}}{P_{c_{\mathrm{H}_{2} \mathrm{O}_{2}}} / P_{c_{\mathrm{H}_{2} \mathrm{O}}}}$; $T_{r}=\frac{T}{T_{c_{\mathrm{H}_{2} \mathrm{O}_{2}}} / T_{c_{\mathrm{H}_{2} \mathrm{O}}}} \quad T_{r}^{0}=\frac{T^{0}}{T_{c_{\mathrm{H}_{2} \mathrm{O}_{2}}} / T_{c_{\mathrm{H}_{2} \mathrm{O}}}}$; $P$ and $T$ - current pressure and temperature; $P^{0}=0.098 \mathrm{MPa}$ and $T^{0}=298 \mathrm{~K}-$ reference values of pressure and ${ }_{\text {temperature; }} P_{c_{\mathrm{H}_{2} \mathrm{O}_{2}}} T_{c_{\mathrm{H}_{2} \mathrm{O}_{2}}} P_{c_{\mathrm{H}_{2} \mathrm{O}} \text { and }} T_{c_{\mathrm{H}_{2} \mathrm{O}}}$ critical parameters of $\mathrm{H}_{2} \mathrm{O}_{2}$ and water $[31,35]$.

Molecular polarizability $\mathrm{p}$ of oleic acid at high pressures and temperatures is calculated by the following equation [34]:

$$
p_{i}(P, T)=p_{i}\left(P^{0}, T^{0}\right) \frac{\rho_{i}(P, T)}{\rho_{i}\left(P^{0}, T^{0}\right)},
$$


where $P_{i}$ - molecular polarizability of oleic acid with appropriate parameters; $P^{0}=0.098 \mathrm{MPa}$ and $T^{0}=298 \mathrm{~K}-$ pressure and temperature reference values; $\mathrm{P}, \mathrm{T}$ - current parameters; $\rho_{i_{-}}$the density of oleic acid with the appropriate parameters.

The critical parameters of the oleic acid and its density at high values of state parameters are determined by the calculation method $[35,36]$.

To calculate the molecular polarizability $\mathrm{p}$ of an aqueous solution of hydrogen peroxide, the ratio [34] is used:

$$
p_{\text {mix }}(P, T)=\frac{\sum_{1}^{2} x_{i} p_{i} v_{i}}{\sum_{1}^{2} x_{i} v_{i}},
$$

where: $x_{i}, p_{i}, v_{i}$ - molar concentration, molecular polarizability and specific volume of hydrogen peroxide and water $[22,35]$.

To measure the refractive index $n_{D}^{20}$, an IRF-22 refractometer was used [37]. For pycnometers thermostating, an U-10 ultrathermostat and a Huber electronic thermostat with a temperature accuracy not worse than $\pm 0.02 \mathrm{~K}$ were used. Weighing used scales VLA-200 and VLTE-150 with an error equal to, respectively, $\pm 0.0001 \mathrm{~g}$ and $\pm 0.001 \mathrm{~g}$.

\section{RESULT AND DISCUSISON}

An absolutely exact theory eliminates the need for an experiment for any particular case or task within the framework of this theory, with the exception of a limited number of experiments conducted to confirm the correctness of this theory. However, such cases are extremely rare or practically absent. The variant of the absence of a theory with an absolute emphasis on the experiment in an infinite number of special cases, even if we decide, is infinitely costly and practically unreal. The intermediate state of affairs is determined by the totality of the "conceptual" factor of an insufficiently perfect theory, a limited but acceptable amount of experiment and a generalization of experimental data, which makes it possible to predict the behavior of unexplored systems.

Generalizations in the field of chemical reactions kinetics are clearly needed. A review of literature data on the kinetics of the organic compounds oxidation reaction in the aqueous phase under supercritical fluid conditions (SCWO) often shows the existence of disagreements in the values of the activation energy $E_{a}$ even for the same compounds [10, 41-45]. Of course, this complicates the above-mentioned procedure of summarizing the experimental data, but does not make it impossible. Figure 1 shows the values of the activation energy $E_{a}$ of the saturated monohydric alcohols [41, 46-49] and acetic acid [10, 42, 43] as functions of the reduced temperature. The temperature of the cast adopted the critical temperature of the water.

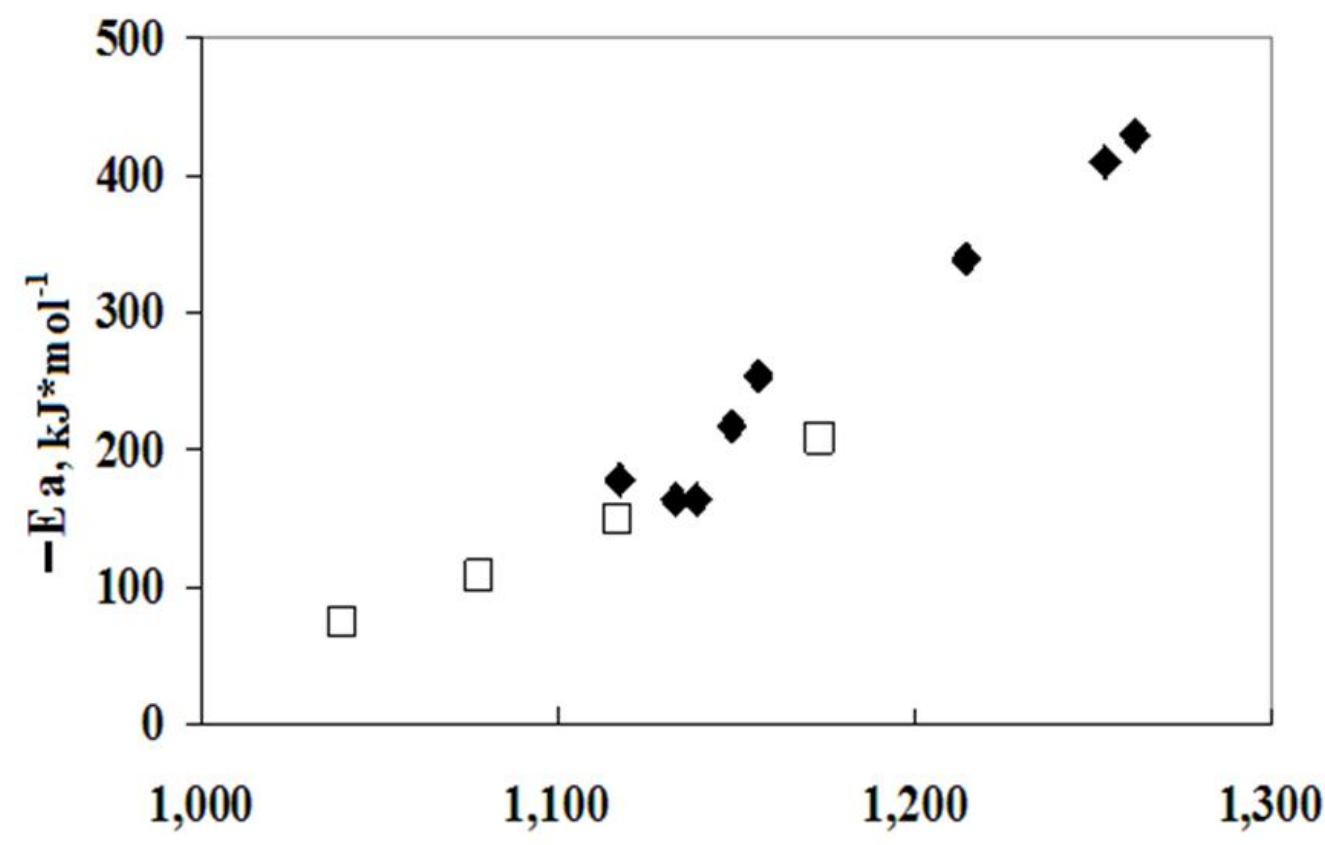

$\tau$

Figure 1: Activation energy $E_{a}$ of the oxidation reaction in an aqueous medium in SCF conditions: $\tau=T / T_{\text {cr }}$ of water; - saturated monohydric alcohols [41,46-49]; $\square$-acetic acid [10, 42, 43] 
In [50, 51], using the Kirkwood theory [52], linear dependences of the oxidation reaction rate constant under $\mathrm{SCF}$ conditions on the dielectric constant in the form ln $k=f(1 / \varepsilon)$ the activation energy with the reaction rate constant $\mathrm{k}$ in the form $k=A \exp \left(-E_{a} / R T\right)$, the dependences of the activation energy $\mathrm{E}_{\mathrm{a}}$ on the dielectric constant $\varepsilon$ are obtained (Fig. 2, 3). Table 1 shows the literature data for the activation energy $E_{a}$ of the oxidation reaction of various chemical compounds in an aqueous medium under SCF conditions, as well as the corresponding dielectric permittivity $\varepsilon$ and dipole moment $\mu$ corresponding to the thermodynamic conditions $[53,54]$.

To establish the general regularity of the interdependence of the activation energy and dielectric constant, molecules with the same type of structure are used. Figure 2 shows the dependences of the activation energy for two homologous series of saturated monohydric alcohols and acids on the value of the dielectric constant $\varepsilon(293 \mathrm{~K})$ oxidized in an aqueous medium in the SCF conditions. As can be seen from the figures, a clear correlation of the discussed characteristics is combined with stratification into groups of substances.

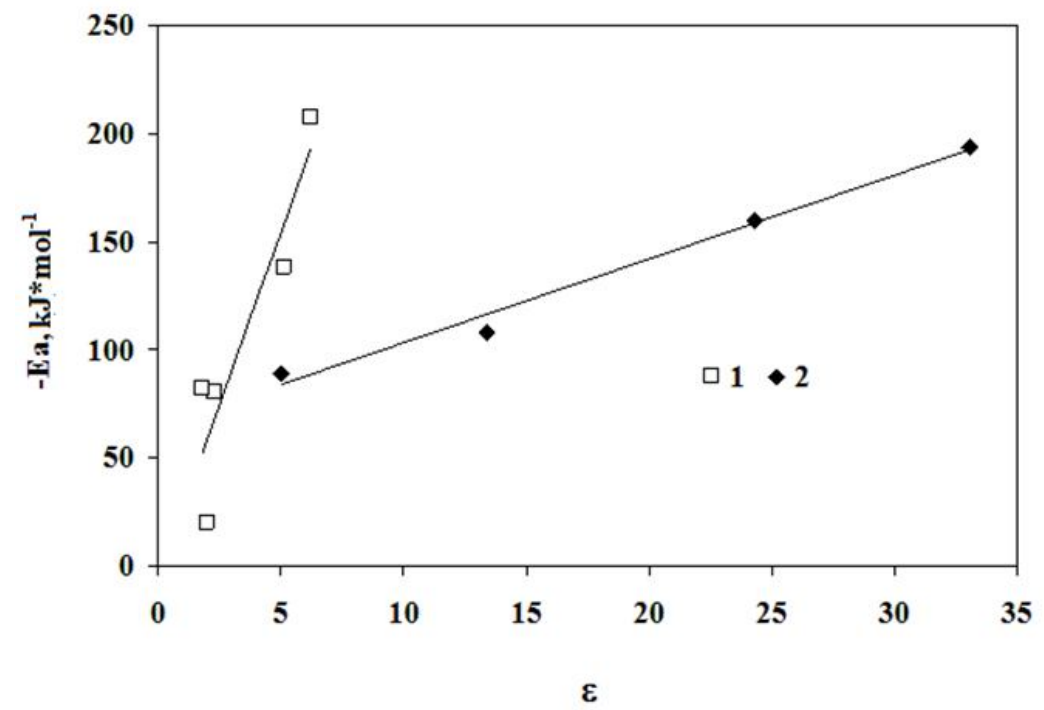

Figure 2: The activation energy of the acids and saturated monohydric alcohols oxidation reaction in an aqueous medium under SCF conditions as a function of $\varepsilon(293 \mathrm{~K})$ dielectric constant of oxidizable reagents: 1 - acids [10, 42, 43]; 2 - alcohols [41,46-49].

Another picture is observed if, as an argument, we use the the conditions for the chemical reaction (Fig. 3). dielectric constant $\varepsilon$ value of the oxidized reagent that meets

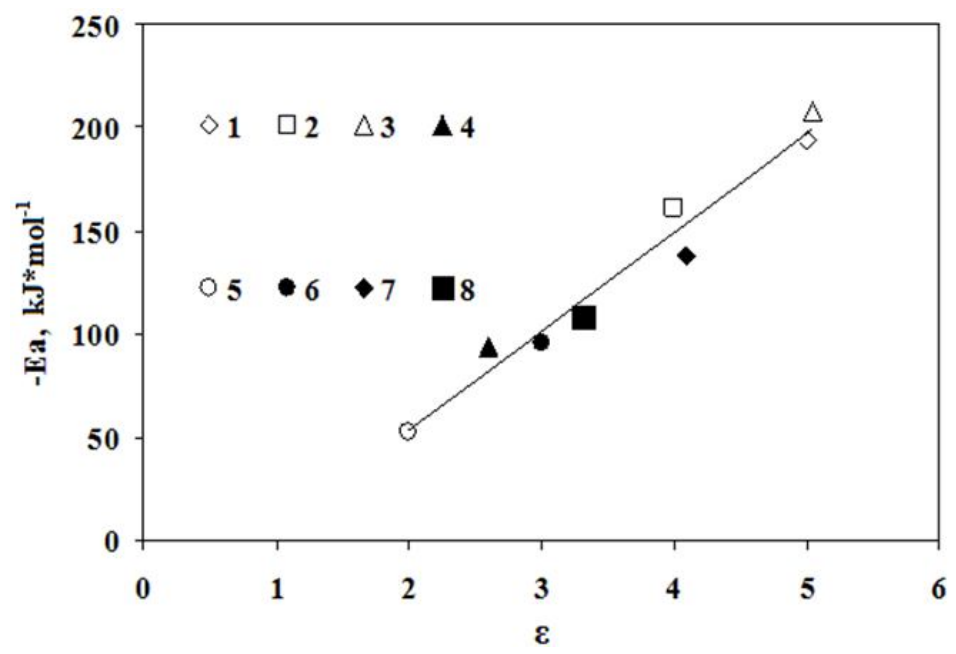

Figure 3: The activation energy in the framework of the chemical compounds oxidation reaction in an aqueous medium under SCF conditions as a function of the dielectric constant $\varepsilon(\mathrm{P}, \mathrm{T})$ of the oxidizable reagents: 1-methanol [41]; 2-ethanol [41]; 3-acetic acid [10]; 4-oleic acid [present work]; 5-acrylic acid [55]; 6-adipic acid [56]; 7-phthalic acid [56]; 8- phenol [58]. 
The calculation of the chemical compounds dielectric constant under high parameters of the state, and, including, in supercritical fluid conditions, is difficult. Taking into account the relationship between $\varepsilon$ and $\mu$, we can assume the existence of a correlation between the activation energy and the dipole moment (of the substance to be oxidized, the difference between the dipole moments of the oxidized substance and the reaction medium with or without the dipole moment of the oxidant). The values of the dipole moments of many substances are known and are given in reference books, for example, [53]. In the absence of such, the dipole moment can be calculated through the structural characteristics of substances [54]. As the analysis of the data presented in Table 1 shows, there is a fairly clear correlation between $E_{a}$ and the dipole moment. The best result was obtained for the dependence of $\mathrm{E}_{\mathrm{a}}$ on the difference between the values of the dipole moment of the oxidized substance and the reaction medium $\Delta \mu=\mu-\mu_{\text {water }}$ (Fig. 4). The deviations $\delta \mathrm{E}_{\mathrm{a}}$ of the calculated and experimental data (Table 1) with rare exceptions (methylene chloride $-51.5 \%$, phenol 32.8\%) do not exceed $\pm 25 \%$, which corresponds to the experimental data errors. The obtained dependencies: $E_{a}=300-297 \Delta \mu$ for the case of $\Delta \mu>0$ and $E_{a}=300+824 \Delta \mu$ for the case of $\Delta \mu<0$, in principle, can make it possible to predict the activation energy values for other compounds oxidized in an aqueous medium in SCF conditions. However, a deeper understanding of the result and a more rigorous assessment of the range of substances corresponding to this correlation is required.

Table 1:The activation energy $E_{a}$ of an oxidation reaction in an aqueous medium under SCF conditions, and also the dielectric constant $\varepsilon$ and dipole moment $\mu$ of oxidizable reagents corresponding to these conditions

\begin{tabular}{|l|l|l|l|l|l|l|l|}
\hline Oxidizable reagent & $\begin{array}{c}\varepsilon(293 \mathrm{~K}) \\
{[23,24]}\end{array}$ & $\varepsilon^{*}$ & $\begin{array}{l}\mu, \mathrm{D} \\
{[53]}\end{array}$ & $-\mathrm{Ea}, \mathrm{kJ}^{*} \mathrm{~mol}^{-1}$ & $-\mathrm{Ea}^{*}, \mathrm{~kJ}^{*} \mathrm{~mol}^{-1}$ & $\delta \mathrm{Ea}, \%$ & $\begin{array}{l}\text { literature } \\
\text { source }\end{array}$ \\
\hline Methanol & 33.1 & 5 & 1.69 & $\begin{array}{l}193.7 \\
167\end{array}$ & 168.1 & $15.2-0.7$ & $\begin{array}{l}{[41]} \\
{[41]}\end{array}$ \\
\hline Ethanol & 24.3 & 4 & 1.7 & 160.5 & 176.4 & -9 & {$[41]$} \\
\hline Butanol & 17.8 & 4 & 1.75 & 163 & 217.6 & 25.1 & {$[45]$} \\
\hline Ethylene glycol & 41.82 & 5 & 2.28 & $\begin{array}{l}160.5 \\
171\end{array}$ & 157.2 & $\begin{array}{l}2.1 \\
8.8\end{array}$ & {$[41]$} \\
\hline Acetic acid & 6.2 & 5 & 1.74 & 208 & 209.3 & 5.1 & {$[10]$} \\
\hline Acrylic acid & 2.0 & - & 2.57 & 52 & 60.96 & -14 & {$[55]$} \\
\hline Adipic acid & $1.8[21]$ & - & 2.5 & 82 & 84.2 & -3 & {$[56]$} \\
\hline Phthalic acid & 5.1 & - & 2.3 & 138 & 150.6 & -8 & {$[56]$} \\
\hline Phenol & 13.4 & - & 1.6 & 124.7 & 93.9 & 32.8 & {$[45]$} \\
{$[58]$}
\end{tabular}

$\mathrm{Ea}, \mathrm{Ea}^{*}$ - experimental and calculated value of the activation energy; $\delta$ Ea - the deviation of the experimental data from the generalization curve; $\varepsilon^{*}$ - the calculated value of the dielectric

constant, obtained using relations (3) - (6), for the SCWO conditions. 


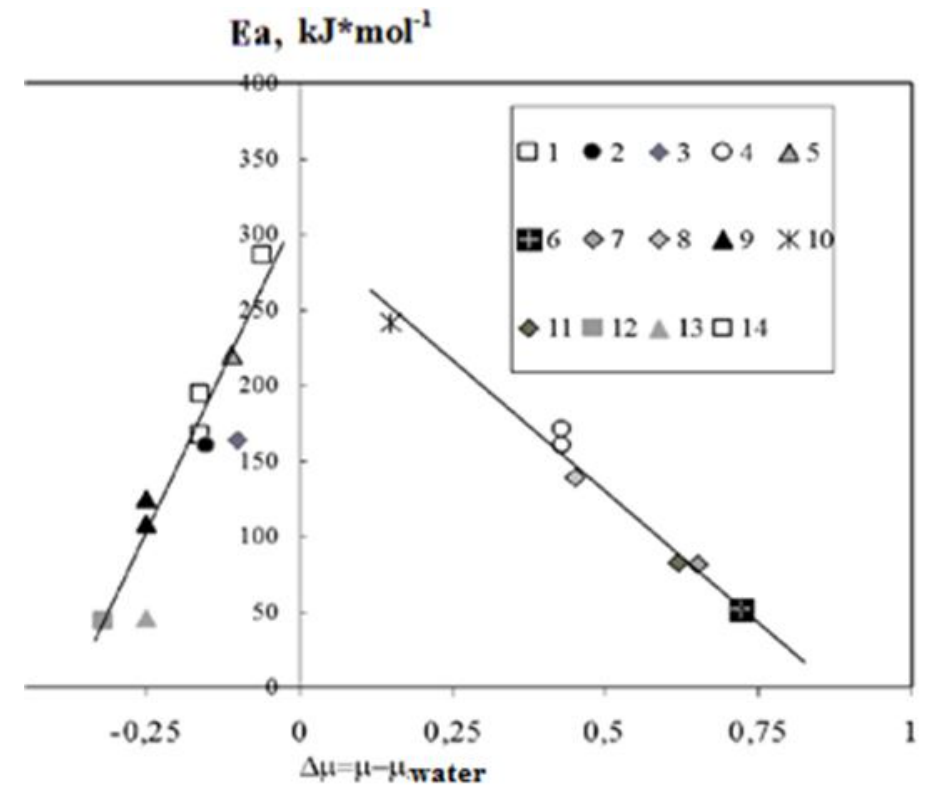

Figure 4: The activation energy of the chemical compounds oxidation reaction in an aqueous medium under SCF conditions as a function of the difference between the dipole moments of the oxidized substance and the reaction medium $\Delta \mu=\mu$ - $\mu_{\text {water }}: 1$-methanol [41]; 2-ethanol [41]; 3-butanol [46]; 4-ethylene glycol [41]; 5-acetic acid [10]; 6-acrylic acid [55]; 7-adipic acid [56]; 8-phthalic acid [56]; 9-phenol [52]; 10-methylphosphonic acid [57]; 11-oleic acid [present work]; 12 thioglycol [58]; 13-methylene chloride [10]; 14-1,1,1 trichloroethane [10]

To confirm the possibility of the method of calculating the activation energy, kinetic studies of the oleic acid with hydrogen peroxide oxidation in an aqueous medium under supercritical fluid conditions have been carried out.

The choice for the study of a "softer" temperature range $(673-723 \mathrm{~K})$ is due to the capabilities of the experimental setup. Although from the point of view of mutual solubility of the reagents, the most preferable temperature range is 750-800K (Fig.5). Regarding the phase state of the reaction mixture "water - oleic acid - hydrogen peroxide" with a molar ratio of 0.96:0.008:0.032, the following should be noted: there are no literature data; special experimental research is expensive in resources and is long in time; The investigated range of state parameters uniquely determines the supercritical fluid state for pure water, and finally, in the cases required in the analysis, it is assumed that a high-pressure optical cell is used to visualize the phase state of the discussed ternary system. Figure 6,7 presents the results of an experimental study of the kinetics of the reaction under discussion.

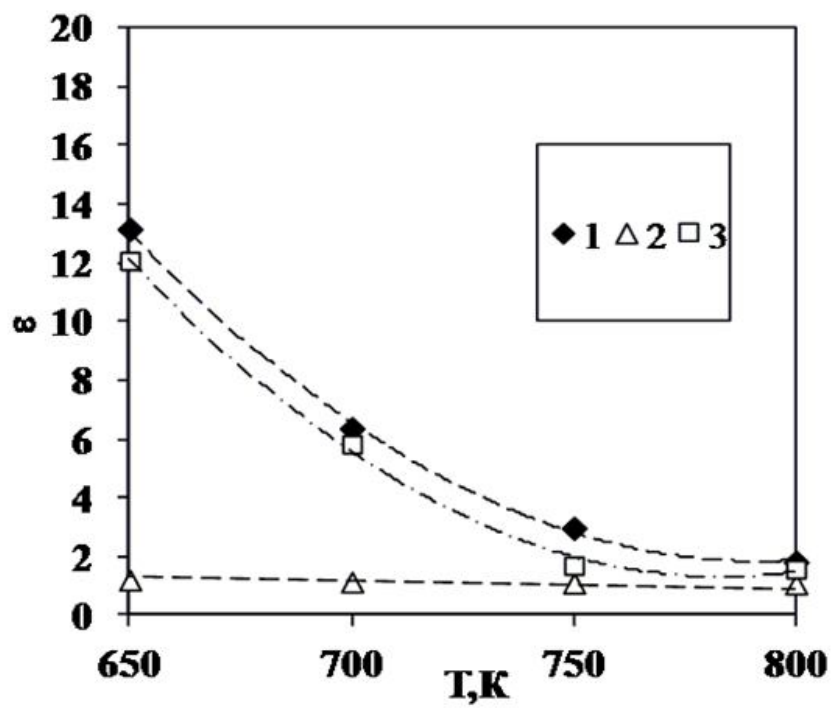

Figure 5: The dielectric constant of the reaction mixture components at $\mathrm{P}=20-30 \mathrm{MPa}$ (calculated by relations (3) - (6)): 1 - water [18]; 2-oleic acid; 3-30\% aqueous solution of hydrogen peroxide 


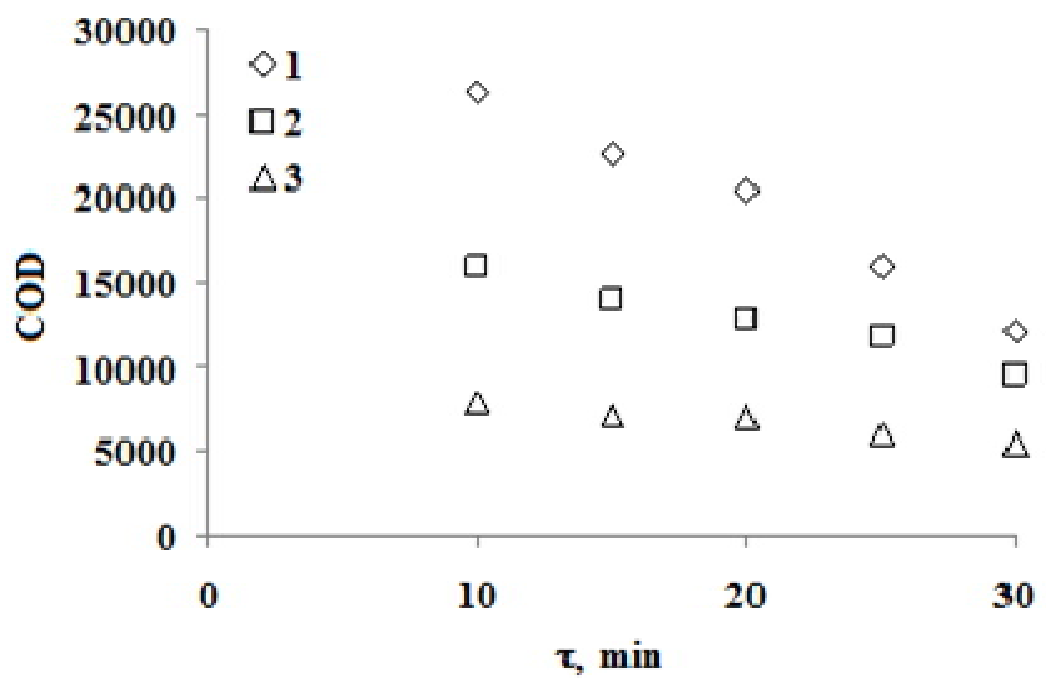

Figure 6: $\mathrm{COD}\left(\mathrm{mgO}_{2} / \mathrm{l}\right)$ of the reaction product of the oleic acid with hydrogen peroxide oxidation in an aqueous medium in SCF conditions: $\diamond-673 \mathrm{~K} ; \square 698 \mathrm{~K} ; \Delta^{-} 723 \mathrm{~K}$

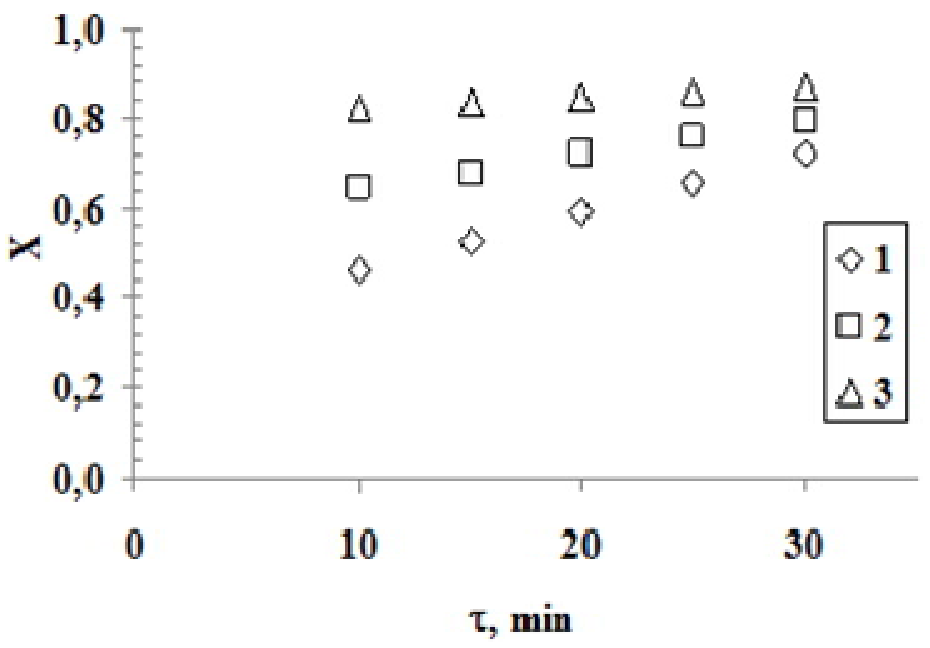

Figure 7: The oleic acid oxidation degree $X$ for the reaction carried out at $P=30 \mathrm{MPa}: \diamond-673 \mathrm{~K} ; \square-698 \mathrm{~K} ; \Delta^{-} 723 \mathrm{~K}$

To describe the kinetics of oleic acid oxidation by hydrogen peroxide in an aqueous medium under SCF conditions, a first-order kinetic model proposed by Imteaz and Shanableh was adopted [11]. It is based on kinetic studies of $\mathrm{Li}$ et al. [38], who established that the reaction order of the SCWO with respect to the organic reagent is equal to one, and when using hydrogen peroxide as the oxygen source in supercritical water, the oxidation rate does not depend on the oxygen concentration. Thus, the chemical reaction according to [11] can be represented as an equation [11]:

$$
\frac{d(X+Y)}{d \tau}=-A \cdot E X P\left(-E_{a} / R T\right) \cdot[X+Y]
$$

where $(\mathrm{X}+\mathrm{Y})$ - COD; $\mathrm{A}$ - pre-exponential coefficient; $\mathrm{E}_{\mathrm{a}}$ activation energy; $\mathrm{R}$ - the gas constant; $\tau$-the time; $\mathrm{T}$ temperature. The integral equation for the oxidation of oleic acid can be expressed as follows:

$$
\ln [\mathrm{X}+\mathrm{Y}]_{\tau} /[\mathrm{X}+\mathrm{Y}]_{0}=-k \tau,
$$

where $[\mathrm{X}+\mathrm{Y}]_{\tau}$ and $[\mathrm{X}+\mathrm{Y}]_{0}-\mathrm{COD}$ reagents in the current $\tau$ and the initial moments of 0 time.

Fig. 8 shows the graphs of experimental data as $\ln [\mathrm{X}+\mathrm{Y}]_{\tau} /[\mathrm{X}+\mathrm{Y}]_{0}$, depending on the reaction time $\tau$ at reaction temperatures of 673,698 and $723 \mathrm{~K}$. 


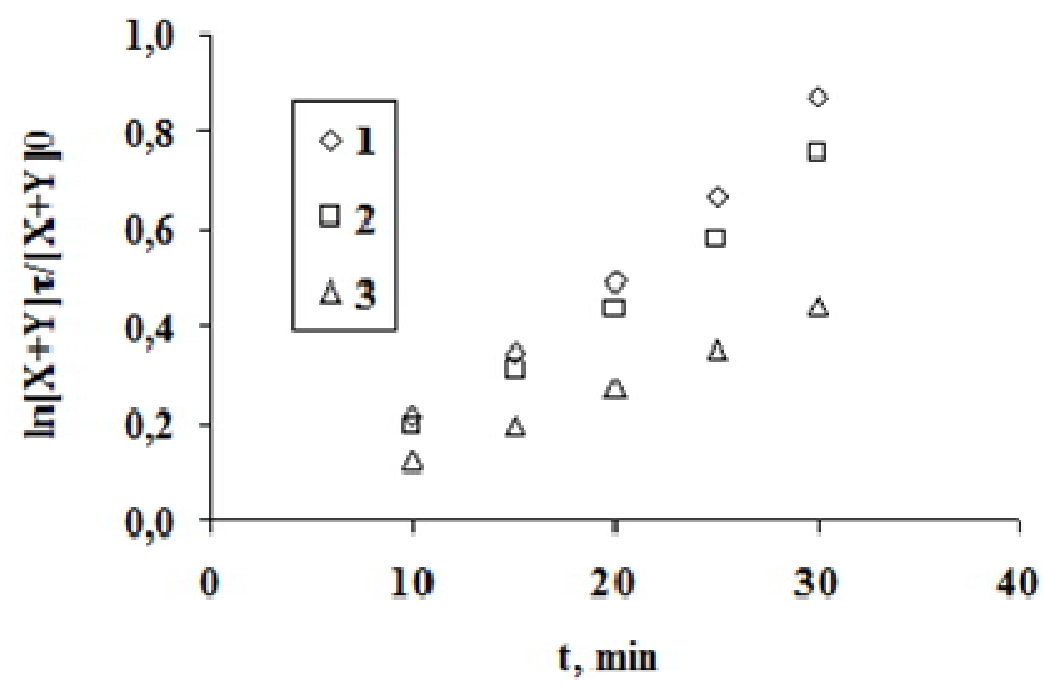

Figure 8: The graphs of experimental data $\ln [\mathrm{X}+\mathrm{Y}]_{\tau} /[\mathrm{X}+\mathrm{Y}]_{0}$ depending on the reaction time $\tau$ at reaction temperatures: $1-673 \mathrm{~K}$; 2-698K; 3-723K.

The reaction rate constant $\mathrm{k}$ and the activation energy $\mathrm{E}_{\mathrm{a}}$ are calculated, respectively, using relations (8) and (9):

$$
k=A \exp \left(-E_{a} / R T\right)
$$

The rate constant values $\mathrm{k}(673 \mathrm{~K})=6,2 \cdot 10^{-4} \mathrm{~s}^{-1}$, $\mathrm{k}(698 \mathrm{~K})=4,74 \cdot 10^{-4} \mathrm{~s}^{-1}$ and $\mathrm{k}(723 \mathrm{~K})=1,68 \cdot 10^{-4} \mathrm{~s}^{-1}$ were obtained from the slope of these straight lines, and the activation energy $E_{a}=-104,7 \mathrm{~kJ}^{*} \mathrm{~mol}^{-1}$ and $\ln A=30.6 \mathrm{~s}^{-1}$. The resulting value differs from that calculated by the generalized dependence (Table 1), no more than $11 \%$.
According to Figure 7, the maximum conversion in the investigated temperature range for the selected composition of the reaction mixture falls at $\mathrm{T}=723 \mathrm{~K}$ and the reaction time is 30 minutes.

At the same time, chromatographic analysis of the obtained intermediate reaction product samples (Fig. 9) and the reaction product of the oleic acid SCWO (Fig. 10) showed the absence of oleic acid in the samples. This conclusion follows from the main peaks in the chromatogram, the only peak in both cases is at the time of exit 0.96 . It corresponds to ethanol in which the sample to be analyzed is dissolved.

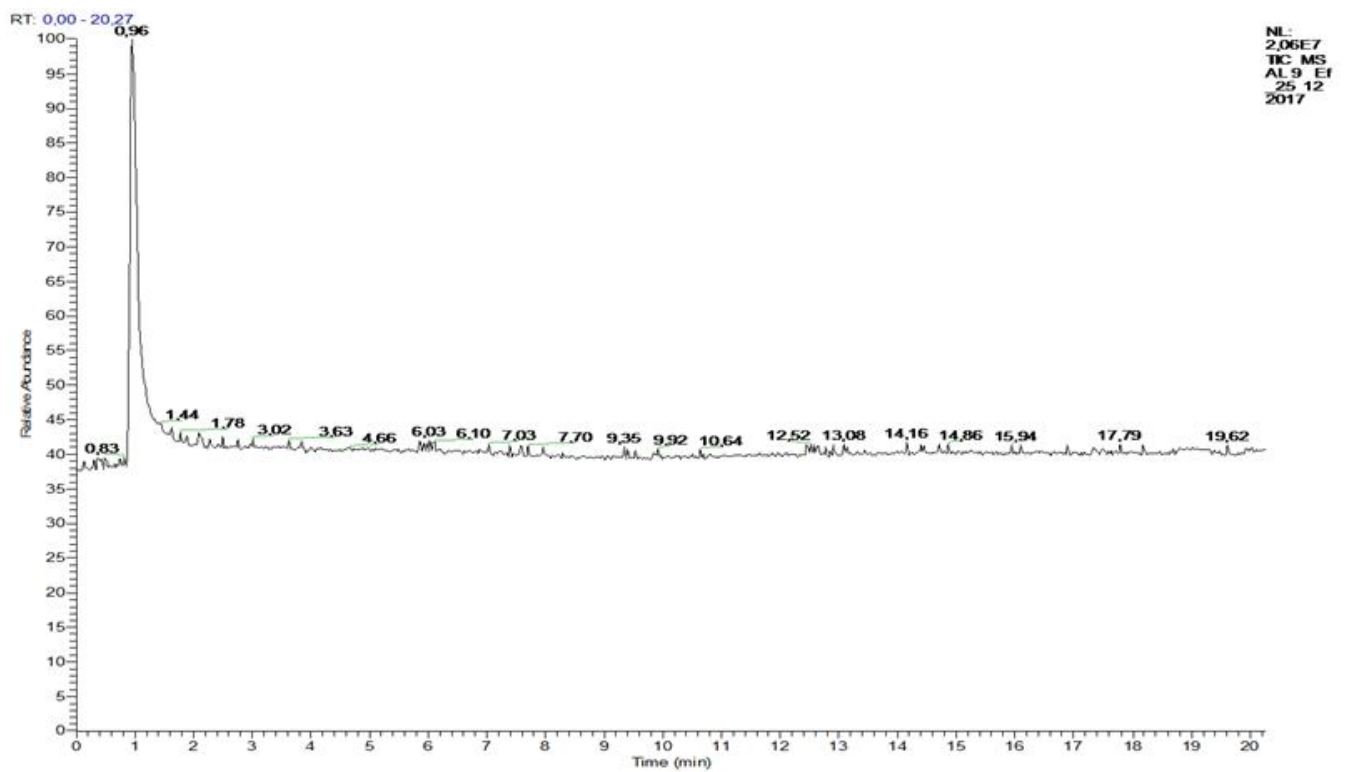

Fig. 9. Chromatogram of an intermediate sample of the reaction product of the oleic acid SCWO; $\mathrm{P}=29.4 \mathrm{MPa}, \mathrm{T}=723 \mathrm{~K}, \tau=30$ $\min$ 


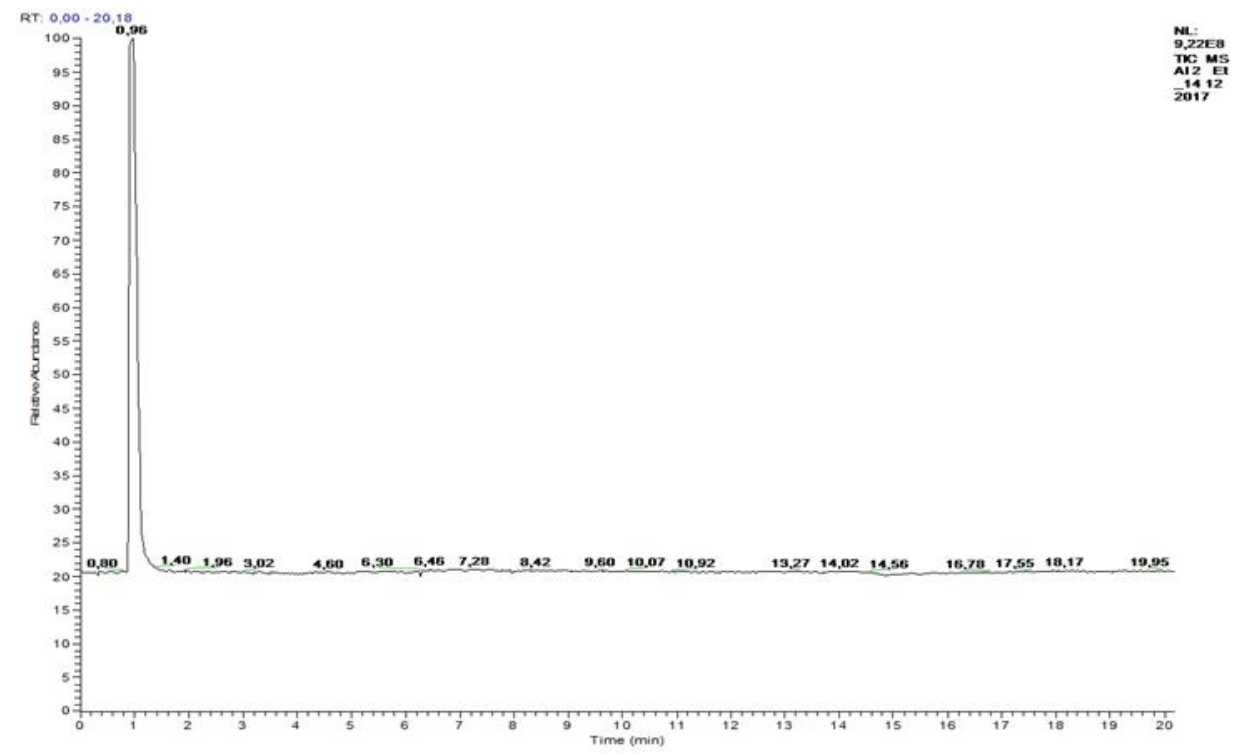

Fig. 10. Chromatogram of the oleic acid SCWO reaction product sample; $P=29.4 \mathrm{MPa}, \mathrm{T}=723 \mathrm{~K}, \tau=30 \mathrm{~min}$.

On the IR spectrum of the six samples of the oleic acid SCWO reaction product, which were obtained additionally for research on the IR spectrum with a time interval from 5 to 30 minutes (with an interval of 5 minutes), characteristic oscillations $(\mathrm{C}=0)$ are clearly visible in the region $1712 \mathrm{~cm}^{-1}$ and vibrations of the carboxyl group - 2600-3200 $\mathrm{cm}^{-1}$ (Fig. 11). In addition, the structure of the hydrocarbon skeleton is confirmed by the absorption bands at $2900 \mathrm{~cm}^{-1}$ (stretching vibrations of $\mathrm{C}_{\mathrm{sp} 3}-\mathrm{H}$, the band is blocked by the absorption band of the $\mathrm{OH}$ group). The broadening of the absorption band of the hydroxy group is due to the formation of acid dimers linked by strong intermolecular hydrogen bonds. In the IR spectra, there are deformation vibrations of the $\mathrm{CH}_{3}$ and $\mathrm{CH}_{2}$ groups at frequencies of $1460,1380 \mathrm{~cm}^{-1}$. The samples absorption spectra obtained practically coincide with the IR spectrum of acetic acid [39, 49].

The refractive indices of the fluid (all six samples) are equal to $1.3726 \div 1.3740$ (acetic acid $=1.3718$ [40]). Thus, it can be stated that the samples obtained from the products of the oleic acid oxidation are aqueous solutions of acetic acid. 


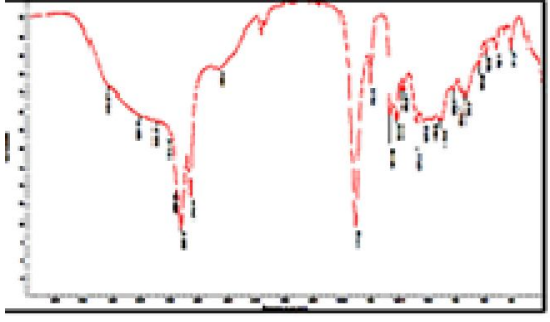

a)

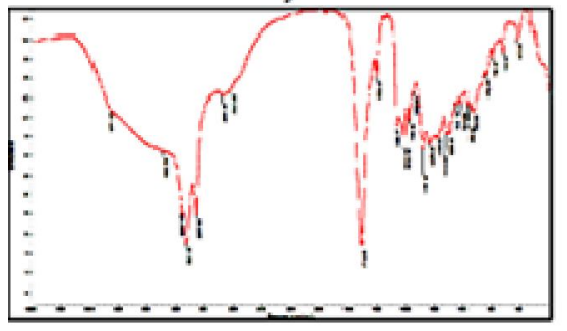

c)

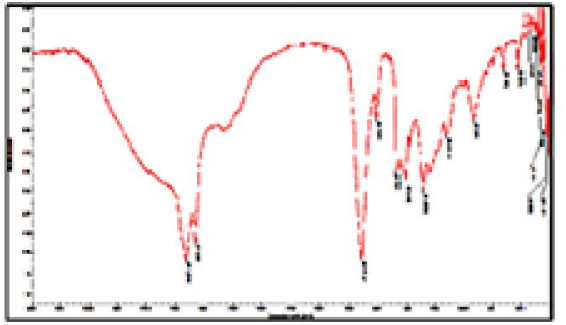

e)

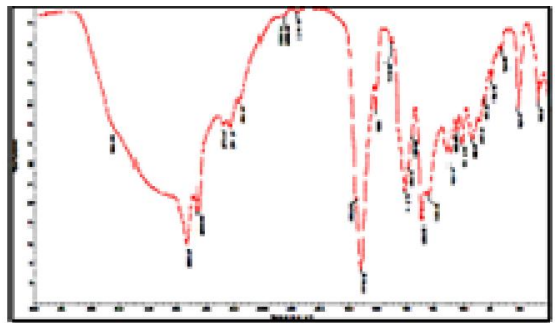

b)

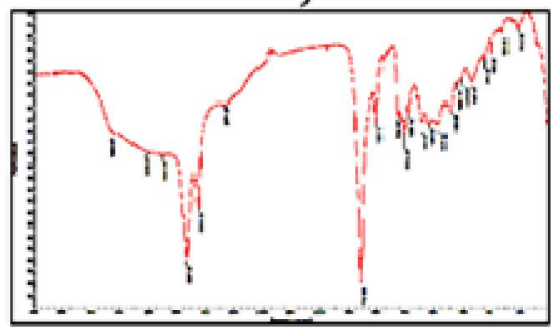

d)

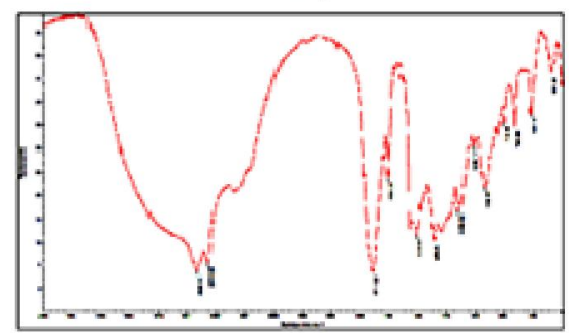

f)

Fig. 11. IR spectra of the oleic acid oxidation reaction products at $T=723 \mathrm{~K}$ : a) 5 minutes; b) 10 minutes; c) 15 minutes; d) 20 minutes; e) 25 minutes; f) 30 minutes

\section{CONCLUSION}

The character of the change in the activation energy as a function of the reduced temperature, the dielectric constant, and the difference in the dipole moment of the oxidized reactant and the reaction medium was revealed for the first time. The generalized dependences are obtained for the activation energy of the chemical compounds oxidation reaction in an aqueous medium in SCF conditions for acids and alcohols, which describe experimental data with an average error of $\pm 25 \%$. The behavior of the dielectric constant of oleic acid and an aqueous solution of hydrogen peroxide (in the presence of literature data for water) in the temperature range $650-800 \mathrm{~K}$ and in the pressure range 200-300 bar has been established. According to Semenchenko V.K. [30], the preferred temperature range $(750-800 \mathrm{~K})$ for the oxidation reaction was established, which ensures the maximum solubility of the oxidized reagent and oxidizing agent in the reaction medium.

The kinetics of the oleic acid with hydrogen peroxide oxidation reaction in an aqueous medium under SCF conditions was studied and the behavior of the chemical reaction characteristics in the temperature range $673-723 \mathrm{~K}$ was found for the water-oleic acid-hydrogen peroxide system ratio of 0.96: 0.008: 0.032 . The activation energy of the oleic acid oxidation by hydrogen peroxide in an aqueous medium under supercritical fluid conditions $\mathrm{E}_{\mathrm{a}}=-104.8 \mathrm{~kJ}^{*} \mathrm{~mol}^{-1}$ differs from the calculated one by no more than $11 \%$.

\section{ACKNOWLEDGEMENT}

The authors are grateful to the Russian Foundation for Basic Research (Agreement No. 18-29-06041) for the financial support of the study.

\section{REFERENCES}

1. F. Cansell, S. Rey, P. Beslin. Thermodynamic aspects of supercritical fluids processing: applications to polymers and wastes treatment. Revue de L'Institut Francais du Petrole, Vol. 53. No. 1, pp. 71-95, 1998.

2. Ph.A. Marrone, G.T. Hong, M.H. Spritzer. Developments in supercritical water as a medium for oxidation, reforming, and synthesis. J. Adv. Oxid. Technol, Vol. 10. No. 1, pp. 157-168, 2007.

3. V. Bambang, K. Jae-Duck. RETRACTED: Supercritical water oxidation for the destruction of toxic organic wastewaters: A review. J. Environ. Sci., No. 19, pp. 513-522, 2007.

4. J. Abeln, M. Kluth, G. Petrich, H. Schmieder. Supercritical water oxidation (SCWO): a process for the 
treatment of industrial waste effluents. High Pressure Research: An International Journal, Vol. 20, No. 1-6, pp. 537-547, 2001.

5. F.M. Gumerov. Supercritical fluid technology. Economic expediency. Kazan: Publishing House of the Academy of Sciences of the Republic of Tatarstan, p. 440, 2019.

6. V.I. Anikeev, A.A. Ermakova. Technique for Complete Oxidation of Organic Compounds in Supercritical Water. Journal tack chemistry, Vol. 84, No. 1, pp. 88-94, 2011.

7. N. Akiya, Ph.E. Savage. Roles of Water for Chemical Reactions in High-Temperature Water. Water. Chem. Rev., Vol. 102, pp. 2725-2750, 2002.

8. A.A. Galkin, V.V. Lunin. Water In Sub- And Supercritical States As A Universal Medium For Chemical Reactions. Advances in chemistry, Vol. 74, No. 11, pp. 24-40, 2005.

9. A.R. Katritzky, D.A. Nichols, M. Siskin, R. Murugan, M. Balasubramanian. Reactions in high-temperature aqueous media. Chem. Rev., Vol. 101. No. 4, pp. 837-892, 2001.

10. S.F. Rice, R.R. Steeper. SteeperOxidation rates of common organic compounds in supercritical water. Journal of Hazardous Materials, Vol. 59, pp. 261-278, 1998.

11. M.A. Imteaz, A. Shanableh. Kinetic Model for the Water Oxidation Method for Treating Wastewater Sludges. Dev. Chem. Eng. Mineral. Proc., Vol. 12., No. 5-6, pp. 515-530, 2004.

12. F.M. Gumerov, R.A. Kayumov, R.A. Usmanov, A.A. Sagdeev, I.Sh. Abdullin, R.F. Sharafeev. Waste Management in Propylene Epoxidation Process with the Use of Supercritical Fluid Media. American J. Anal. Chem., Vol. 3, pp. 950-957, 2012. https://doi.org/10.4236/ajac.2012.312A126

13. E.S. Gayazova. Int. J. Anal. Mass Spectr. Chromat, No. 1, pp. 48-54, 2013.

14. A.A. Vostrikov, O.N. Fedyaeva, I.I. Fadeeva, M.Ya. Sokol. Formation of $\mathrm{Al} 2 \mathrm{O} 3$ nanoparticles during aluminum oxidation by water with sub- and supercritical conditions. Sverkhkriticheskiye flyuidy: teoriya i praktika. Supercritical Fluids: Theory and Practice, V. 5, No. 1, pp. 12-24, 2010.

15. D.L. Sparks, L.A. Estrevez, R. Hernandez. Supercritical-fluid-assisted oxidation of oleic acid with ozone and potassium permanganate. Green Chem., No. 11, pp. 986-993, 2009.

16. E.A. Youssef, G. Nakhla, P.A. Charpentier P. A. Oleic Acid Gasification Over Supported Metal Catalysts in supercritical Water: Hydrogen Production and Product Distribution. Int. J. Hydrogen Energy. 2011.Vol. 36. No. 8. P. 4830-4842.

17. D.W. de Leeuw. Supercritical water gasification. Decomposition of lipids forming a substantial part of sewage sludge, 2017.

18. A. Takahashi, N. Kitakawa, T. Yonemoto. Kinetic Analysis for Oxidation of Oleic Acid. J. Chem. Eng. Japan., Vol. 33, No. 3, pp. 481-488, 2000. https://doi.org/10.1252/jcej.33.481

19. A.N. Vinogradov. Moscow University Chemistry Bulletin, Vol. 45, No. 5, pp. 305-308, 2004.
20. F.O. Ceden, M.M. Prieto, J. Xiberta. Measurements and Estimate of Heat Capacity for Some Pure Fatty Acids and Their Binary and Ternary Mixtures. J. Chem. Eng. Data., Vol. 45, pp. 64-69, 2000.

21. Z.I. Zaripov, G.Kh. Mukhamedzyanov, S.A. Bulaev, F.N. Shamsetdinov. Thermodynamic and Caloric Properties Of Oleic Acid In A Wide Range Of Pressures. Bulletin of Kazan Technol. Univ., 3, pp. 44-50, 2011.

22. NIST Standard Reference Database 23. NIST Reference Fluid Thermodynamic and Transport Properties Database (REFPROP): Version 9.0. Retrieved from: www.nist.gov

23. H.R. Holgate, J.W. Tester. Fundamental Kinetics and Mechanisms of Hydrogen Oxygen in Supercritical Water. Combustion Science and Technology. Vol. 88, No. 5, pp. 369-397, 1993. https://doi.org/10.1080/00102209308947245

24. A.V. Kurdyukov, A.R. Gabitova, F.M. Gumerov. Elementary acts of supercritical water oxidation (SCWO) model analogs fatty acid triglycerides in supercritical fluid media. Butlerov Communications, Vol. 44, No. 10, pp. 153-197, 2015.

25. R.R. Gabitov, R.A. Usmanov, F.M. Gumerov, F.R. Gabitov. Bulletin of Kazan Technol. Univ., Vol. 15(7), pp. 129-132, 2012.

26. W.J. Gong, F. Li, D.L. Li. Processing of the 10th international conference on environment science and technology. Kos Island, Greece, 2007. P.A432-A439.

27. GOST 31859-2012. State standard. Water. Method for the determination of chemical oxygen demand.

28. E. Croiset, S.F. Rice, R.G. Hanush. Hydrogen peroxide decomposition in supercritical water. AIChE J., Vol. 43, No. 9, pp. 2343-2352, 1997.

29. F.M. Jin, A. Kishita, T. Moriya, H. Enomoto. Kinetics of oxidation of food wastes with $\mathrm{H} 2 \mathrm{O} 2$ in supercritical water. J. Supercritical Fluids, Vol. 19, pp. 251-262, 2001.

30. F.M. Gumerov, A.A. Sagdeev, D.G. Amirkhanov. Solubility of substances in supercritical fluid environments. LAP Lambert Academic Publishing, pp. 336, 2016.

31. M. Uematsu, E.U. Frank. Static Dielectric Constant of Water and Steam. J. Phys.Chem. Ref. Data, Vol. 9, No. 4, pp. 1291-1304, 1980. https://doi.org/10.1063/1.555632

32. Ch. Wohlfahrt. Landolt-Börnstein - Group IV Physical Chemistry 6 (Static Dielectric Constants of Pure Liquids and Binary Liquid Mixtures). Springer-Verlag Berlin Heidelberg, 1991. Retrieved from: http://materials.springer.com/lb/docs/sm_lbs_978-3-540 -47619-1_310.1007/10047452_3

33. F.F. De Sousa. Dielectric Properties of Oleic Acid in Liquid Phase. J. Bionanosci, Vol. 3, pp. 1-4, 2010.

34. P. Wang, A. Anderko. Computation of dielectric constants of solvent mixtures and electrolyte solutions. Fluid Phase Equilib, Vol. 186, pp. 103-122, 2001.

35. R. Reed, D. Prausnits, T. Sherwood. Properties of gases and liquids: A Handbook. L.: Chemistry, pp. 592, 1982.

36. S. Bretshnaider. Properties of gases and liquids. Engineering calculation methods. Leningrad: Chemistry, pp. 536, 1966. 
37. GOST18995.2-73. Liquid chemical products. Method for determining the refractive index.

38. L. Li, P. Chen, E.F. Gloyna. Generalized kinetic model for wet oxidation of organic compounds. AlChE Journal, Vol. 37, No. 11, pp. 1687-1697, 1991.

39. NIST Chemistry WebBook. https://webbook.nist.gov/chemistry/

40. A.A. Ravdel, A.L. Ponomareva. Quick reference physico-chemical quantities. Leningrad: Chemistry, p. 14, 1983.

41. J. Mercadier, F. Marias, S. Vielcazals, F. Mancini, M. Bottreau, F. Cansell. Supercritical Water Oxidation of Organic Compounds: Experimental and Numerical Results. Environ. Eng. Sci., Vol. 24, No. 10, pp. 1379-1388, 2007.

42. P.E. Savage, M.A. Smith. Kinetics of acetic Acid oxidation in supercritical water. Environ. Sci. Techn., Vol. 29, pp. 216-221, 1995.

43. J.C. Meyer, Ph.A. Marrone, J.W. Tester. Acetic acid oxidation and hydrolysis in supercritical water. AIChE J., Vol. 41, No. 9, pp. 2108-2121, 1995. https://doi.org/10.1002/aic.690410910

44. M. Krajnc, J. Levec. On the kinetics of phenol oxidation in supercritical water. AIChE J., Vol. 42, No. 7, pp. 1977-1984, 1996.

45. J.R. Portela, E. Nebot, E.J. Martinez de la Ossa. Kinetic comparison between subcritical and supercritical water oxidation of phenol. J.Chem. Eng., Vol. 81, pp. 287-299, 2001.

46. R.K. Heiling, J.W. Tester. Oxidation of simple compounds and mixtures in supercritical water: carbon monoxide, ammonia and ethanol. Environ. Sci. Technol., Vol. 22, pp. 1319-1324, 1988.

47. J.H. Lee, N.R. Foster. Oxidation of methanol in supercritical water. J. Ind. Eng. Chem, Vol. 5, No. 2, pp. 116-122, 1999.

48. F. Vogel, J.L. Blanchard Di Naro, P.A. Marrone, S.F. Rice, P.A. Webley, W.A. Peters, K.A. Smith, J.W.J. Tester. Critical review of kinetic data for the oxidation of methanol in supercritical water. Supercritical Fluids, Vol. 34, pp. 249-286, 2005.

49. J. Schanzenbacher, J.D. Taylor, J.W.J. Tester. Ethanol oxidation and hydrolysis rates in supercritical water. Supercritical Fluids, Vol. 22, pp. 139-147, 2002.

50. K.A. Connors. In Chemical Kinetics: Study of Reaction Rates in Solution. VCH: New York, pp 407, 1990.

51. K.M. Benjamin, P.E. Savage. Hydrothermal reactions of methylamine. J. Supercritical Fluids, Vol. 31, pp. 301-311, 2004.

52. J.G. Kirkwood. Theory of Solutions of Molecules Containing Widely Separated Charges with Special Application to Zwitterions. J. Chem. Phys., Vol. 2., p. 351, 1934. https://doi.org/10.1063/1.1749489

53. O.A. Osipov, V.I. Minkin. Handbook of dipole moments. Publishing House of Higher School, p. 264, 1965.

54. V.I. Minkin, O.A. Osipov, Yu.A. Zhdanov. Dipole moments in organic chemistry. L: Chemistry, p. 246, 1968.
55. Y.M. Gong, S.Z. Wang, X.Y. Tang, D.H Xu, H.H. Ma. Supercritical water oxidation of acrylic acid production wastewater. Environ. Techn., Vol. 35. No.7, pp. 907-916, 2014.

56. S.H. Ahn, S.N. Joung, K. Yoo Min, J. Noh, J. Hee Han, S. Ho Han. Oxidation characteristics of phthalic and adipic acids by supercritical water. Korean J. Chem. Eng., Vol. 15. No. 4, pp. 390-395, 1998.

57. S. Bianchetta, L. Li, E.F. Gloyna. Supercritical water oxidation of nethylphosphonic acid. Ind. Eng. Chem. Res, Vol. 38, pp. 2902-2910, 1999. https://doi.org/10.1021/ie990094p

58. B. Veriansyah, J.D. Kim, J.C. Lee. Supercritical Water Oxidation of Thiodiglycol. Ind. Eng. Chem. Res., Vol. 44, pp. 9014-9019, 2005. https://doi.org/10.1021/ie050482t 